Boise State University ScholarWorks

10-1-2009

\title{
Counseling and Therapy in Video
}

Memo Cordova

Boise State University

Ellie Dworak

Boise State University 


\section{Counseling and Therapy in Video}

Date of Review: September 4, 2009

Composite Score:

\author{
Reviewed by: Memo Cordova and Ellie Dworak \\ Albertsons Library \\ Boise State University \\ 1910 University Drive \\ Boise, Idaho 83725 \\ $<$ memocordova@boisestate.edu> \\ <elliedworak@boisestate.edu>
}

\section{Pricing Options}

Counseling and Therapy in Video (CTiV) offers two models-purchase or license. The outright purchase varies, but ranges from $\$ 10,400$ to $\$ 35,000$, depending on annual materials budget and FTE; the annual Web Access Fee costs $\$ 250$. Subscription options range from $\$ 1,500$ to $\$ 3,600$ per year depending on number of concurrent users, with $\$ 3,600$ being the unlimited price option. Discounts are offered for consortial purchases, and a variety of package pricing options are available.

\section{Product Description}

$\mathrm{CTiV}$, an Alexander Street Press product, is a growing collection currently comprising over 300 videos. These videos range from approximately 20 minutes to over an hour; the average length is just under an hour. The content includes therapy sessions (actual, reenacted, or scripted), experts discussing therapeutic approaches and analyzing examples, and presentations in which noted therapists lecture about issues in the mental health field. The videos are accompanied by written transcripts, and many include teaching guides. Continuing Education credits are available to therapists for an extra fee.

Alexander Street Press specializes in providing high quality, mostly primary source materials with a discipline focus. They often partner with other organizations. CTiV was published in partnership with several groups, including Psychotherapy.net, Microtraining Associates, and the University of Manchester Department of Psychiatry. The videos are produced by a number of organizations, including Allyn \& Bacon, the American Psychological Association, and The Society for the Psychological Study of Ethnic Minority Issues.

\section{Critical Evaluation}

\section{CONTENT}

The emphasis in CTiV is on, as its title suggests, counseling and its associated therapies. Counseling Psychology, according to the APA Dictionary of Psychology, is

the branch of psychology that specializes in facilitating personal and interpersonal functioning across the lifespan. Counseling Psychology focuses on emotional, social, vocational, educational, health-related, developmental, and organizational concerns ... and addresses issues from individual, family, group, systems, and organizational perspectives. In contrast to a clinical psychologist, who usually emphasizes origins of maladaptations, a counseling psychologist emphasizes adaptation, adjustment, and more efficient use of the individual's available resources.
In keeping with this definition, $\mathrm{CTiV}$ provides a varied collection of videos that illustrates concepts of one-on-one and group interactions.

$\mathrm{CTiV}$ touts itself as "the largest and richest online collection of video available for the study of social work, psychotherapy, psychology, and psychiatric counseling" with good reason. We were impressed with the comprehensiveness of this collection of audiovisual materials, especially when coupled with another Alexander Street Press product, Counseling and Psychotherapy Transcripts, Client Narratives, and Reference Works. That product, now available as an electronic database, was selected as an "2008 Outstanding Academic Title" by Choice Magazine.

The films themselves are well produced and are delivered as high resolution streaming videos with excellent sound quality. Each video is accompanied by a transcript, which scrolls as the video plays, and highlights the corresponding text. We found the videos to be engaging, informative, and easy to follow. The transcripts make it unnecessary for the viewer to take copious notes and also make the product less difficult for the hearing impaired.

A cursory review reveals the range of themes covered. "Race" currently has the highest number of videos available (101 videos), closely followed by "Theory" (97), and "Psychological Issues" and "Family and Relationships" (79 and 61 videos, respectively). Together these themes cover the bulk of topics. Other categories round out the collection, ranging from "Age and Aging" (6 videos) to several such as the generic "Disorders" (with 16 videos). Some of the videos appear dated, due to changes in clothing and hairstyle fashions, and that may be off-putting to users. This, plus the fact that modes of therapy evolve and go out of vogue, presents a challenge for Alexander Street Press. It will have to update the content continuously to reflect current trends in counseling and therapy.

The videos included in this collection can be used freely for educational purposes, ridding faculty and students of worry about copyright restrictions. In today's world of hybrid content and confusion about intellectual property law, it is wonderful to have this anxiety removed.

\section{INTERFACE}

The interface is simple to use. A navigation bar at the top of the page contains all important functions. The main landing page also uses a side-navigation area to itemize the browse functions, which are extensive. A brief description of the database takes up a portion of the screen, with a link to a guided demonstration (in screen capture format). There are also screen shots from several featured videos, which adds an appealing graphical element as well as a sense of the types of content included. 

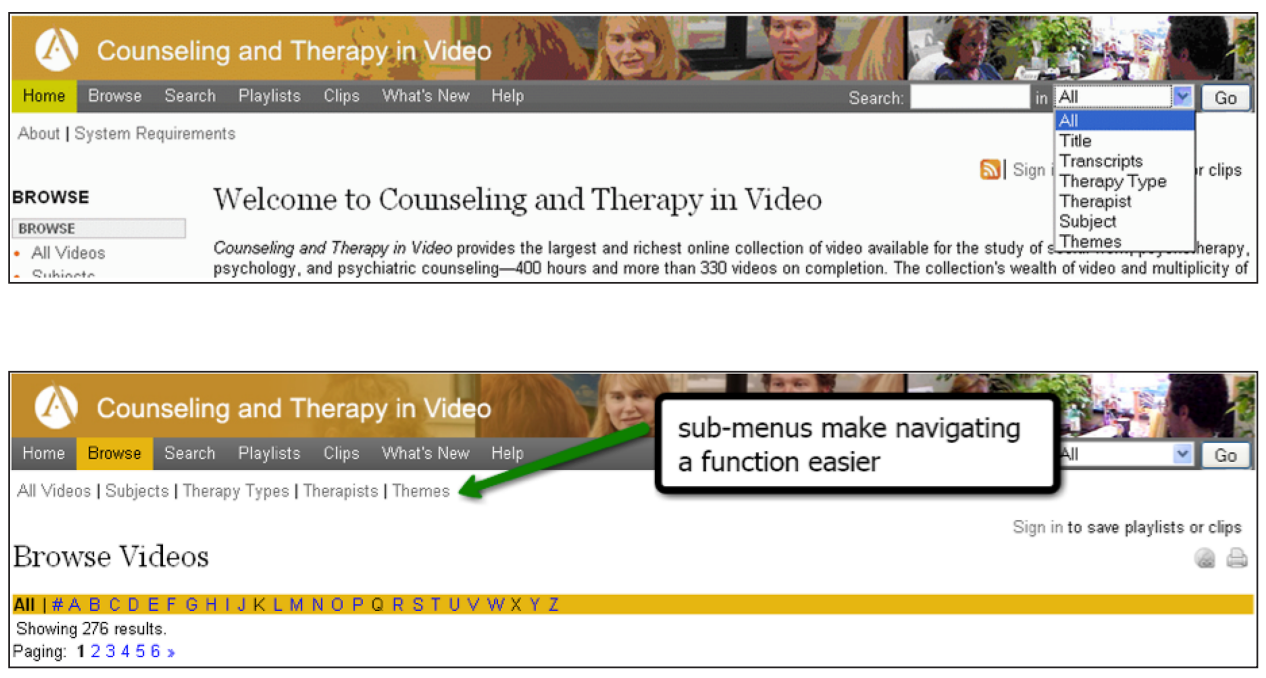

FIGURE 1 The navigation menu at the top of the page is persistent throughout the product.
The navigation menu, included in the banner across the top, is persistent throughout the product. It includes several elements: the database title, which helps orient users to the tool they are using (a small but important detail); a quick search box with a pop-up to select specific fields (see Figure 1); and several menus that allow one to navigate through the various functions of the database.

The menus include options to go to the browse screen, the advanced search screen, playlists (lists of video clips, videos, and outside content created by users, which are described in more detail later), clips (also created by users), what's new, and help. A secondary navigation menu appears beneath the first for the browse, search, playlists, and clips pages (see Figure 2). From a usability standpoint, this combination of persistent navigation menus and context sensitive submenus is useful and well designed.

One must always consider persons with disabilities when selecting educational content, and multimedia presents a special challenge because of the inherent audiovisual nature of the material. The scrolling transcripts are useful in mitigating this problem. As the video plays, the transcript scrolls alongside, with highlighted text, which indicates the current portion of the video. This is an excellent feature for the hearing impaired (who can follow along) and for the visually impaired (who could use a screen reader). Transcripts can also be opened separately from the video and printed for those who need more time to read the material carefully. We e-mailed the collection editor, Greg Urquhart, who asserted that the interface meets the guidelines in Section 508 of the Americans with Disabilities Act, so it should be fully accessible with a variety of adaptive technologies.

The color scheme, layout, and menu placement were both aesthetically pleasing and easy to navigate. Subsequent pages follow the same overall design, which adds to the ease of use. The preview screenshots used throughout add visual value and context.

\section{BROWSE}

The fastest way to access content is via the powerful Browse options: All Videos, Subject, Therapy Types, Therapists, Themes, and Video Types. The All Videos browse option is divided into columns, one column for each of several descriptive categories. Clicking on the column header conveniently resorts the videos by that category.

The Themes, Therapy Types, and Therapists browse categories simply list the headings for the category (for instance, Themes is broken into 23 subheadings such as gender, theory, and work) with a notation of the number of videos available for each. Clicking the number displays a page listing these videos, including basic metadata (title, publisher, year, and duration) and a thumbnail that can be clicked to view the video.

The Subjects browsing screen is somewhat more complex because the assigned subject categories are more specific than the other browse options. The subject screen includes a second level of headings, which is displayed when clicking either the "+" next to a heading or the Hide/Show All Items link (see Figure 3).

As with the other browse categories, the headings include an indicator of the number of videos and are clickable.

\section{SEARCH}

The header on each page includes a simple search box with a dropdown box offering options to search a particular field (Figure 1). Quick Search (to the left) will probably be most valuable to those who already know the collection, subject terminology, or specific therapy or therapist, because it doesn't facilitate complex search queries. The results list for All Fields is broken into categories, showing the number of videos available in each field containing the keyword within the title, transcript, therapy type, subject, etc. (Figure 4). This helps the user locate the most relevant results, because a particular query will have a different meaning if located in a title versus a transcript.

The search results screen is a simple display of each result, similar to the browse results screens. As with the browse results, the search results screen shows a thumbnail of the video and a bit of the portion of the record that matches, with the words highlighted in red. A Refine Your Search option is listed at the top. This is not, in fact, a results refinement, but rather a link to the Advanced Search screen where you can do a more specific search. Users may find it confusing that the original search terms are not included in this refinement option. This is one of the few distractions in an otherwise solid interface.

The Advanced Search page is powerful, with multiple ways to limit and tweak a search. We especially like that most of the fields have a link that opens a pop-up box to select from a list of controlled vocabulary. The options to limit by therapist's gender or race and/or client age, gender, race, or sexual orientation may be useful for practitioners and students. 


\section{FIGURE 3 (Left) The subject screen includes a second level of headings, which is displayed when clicking either the "+" next to a heading or the Hide/Show All Items link.}

FIGURE 4 (Right) The results list for All Fields is broken into categories, showing the number of videos available in each field containing the keyword within the title, transcript, therapy type, subject, etc.

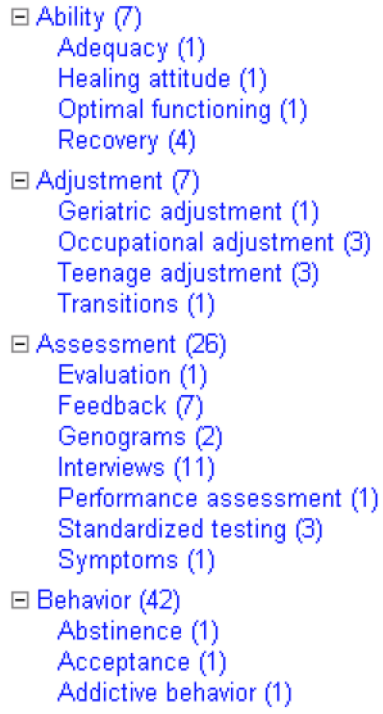

\section{Search Results}

\author{
We found work in: \\ $\gg$ Title (3) \\ - Transcripts (271) \\ \Therapy Type (0) \\ \Therapist (0) \\ Subject (1) \\ Themes (9) \\ Search for work in clips
}

Search for work in playlists
Of note is that the controlled vocabulary is well considered and useful for both experts and the lay person. According to the collection editor, the controlled vocabulary was constructed by Alexander Street Press "with the help of the various reference resources and subject experts." Wisely, where possible, the controlled vocabulary for this collection overlaps with that of Counseling and Psychotherapy Transcripts, Client Narratives, and Reference Works, Alexander Street Press' other major collection in this subject area. Mr. Urquhart noted that drug terms are standardized to Mosby's Drug Consult, diagnostic and therapeutic terms to the $D S M-I V$-TR, and other terms were assigned using the APA Thesaurus (10th edition) as well as other sources and subject experts.

\section{TOOLS}

A useful feature in any database is the availability of a syndicated feed of new titles. CTiV includes the innocuous orange RSS icon, located next to the Sign In to Save Playlists or Clips link on the top-right hand side of the page. However, the actual syndicated feed provides no descriptive value beyond the title of the video. While the power of syndication is useful for current awareness means, the feed itself could be more descriptive, providing richer content to the subscriber by including the abstract of the video, duration, theme(s) and year of publication. We were unable to get the feed to work with popular RSS aggregator Bloglines <http://www.bloglines.com>, though had no trouble with Google Reader <http://www.google.com/reader>.

To access more features the user needs to create an account, and that requires registering with a user name and e-mail address. The process is simple and straightforward. After creating an account, the user will be given the option to build a professional profile and upload a photograph. The profile page has fields for professional contact information (position, department, URL, and phone number) and space for lengthier narratives under About, Subject Expertise/Current Research, and Courses Taught. There is also an option to include Articles Written, replete with Citation and URL, though the Citation feature does not adhere to specific style standards. However, after creating a profile and adding the information, we were unable to go back to our profile pages to make changes or additions. Once logged in to the database, the user can see the Welcome [username] message, links to My Pro- file, and Sign Off, but clicking on My Profile takes him to a simpler page where he can change the display name or e-mail address, reset a password, or sign off. This page is different from the initial profile page, with no obvious link back to the original profile editing page. Individuals who put in time and effort to create and populate a professional profile ought to be able to edit such commonplace identifiers, especially if the profile can be viewed by others in and beyond the institution. However, the authors did not see this feature either, which leads us to wonder why anyone would create a profile at all. Not having a link to a profile is counterintuitive, odd, and not useful.

Logged in users have the benefit of two powerful tools for working with videos: playlists and clips.

Clips are segments of video created by database users. These selected portions of videos can be annotated and saved with a title of the creator's choosing. We were impressed with the simplicity of creating video clips. A scissor icon appears at the top of each video. Clicking on the icon opens a simple dialog box with a line signifying the timeline of the video. One can choose, down to the seconds, specific time frames. After doing so, one simply titles the clip, choose whether it is viewable by just the user, people in one's institution, or "everybody," and save it. Clips made available to other database users can be searched or browsed. The Clips page has links and tabs for All Clips, My Clips, and My Institution's Clips. Within each clip there are options to view, add to a playlist, or embed to an outside Web site

Playlists are themed collections that can include clips, tracks, or whole videos, and relevant materials outside the database (which can include anything with a URL). Like clips, playlists can be made private, available to the institution, or all database users. And, like clips, they are searchable and browseable. A playlist can be annotated as well as titled. Creating a playlist is as intuitive as creating clips. Each video has an Add to Playlist button, which, when clicked, allows the user to create a new playlist or add the item to a current playlist. Items can then be reordered, removed, or annotated.

Both playlists and clips have good functionality and are easy to share; the embed feature is particularly useful since the user can embed just a few seconds, the whole video, or an entire playlist, to a class Web site or course management system. For clips and playlist already in 


\section{$\uparrow$ Counseling and Therapy in Video Review Scores Composite:

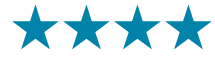

The maximum number of stars in each category is 5 .

\section{Content:}

\section{$\star \star \star \star$}

The content in this database is not only valuable, it is unique. However, it is most appropriate for academic libraries with programs that have a specific need; it is highly recommended to any academic institution that trains counselors, psychologists, or social workers.

\section{Searchability:}

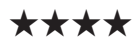

The interface is generally excellent, but would be even better if a few glitches were corrected. More important, it could become an invaluable professional development tool if some attention were given to the social networking and current awareness possibilities. Clearly, however, this vendor has given ample consideration to the product's usability, including accommodating the disabled and all learning styles (by including a text as well as audiovisual component).

\section{Pricing Options:}

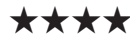

This database is one-of-a-kind and clearly required a great deal of development effort, so the price seems reasonable. As the content is increased and if more development effort is given to the social network aspects, the authors would give this five stars.

\section{Contract Options:}

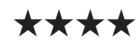

The contract appears to be quite standard, and allows limited print or electronic copies to be made for noncommercial use; print copies may be made for Interlibrary Loan. Given that this is mainly a media product, the ILL option is not incredibly useful, but generally the restrictions are reasonable and valid.

the database (discovered via the browse/search feature), both include the name of the individual that selected a particular clip and/or playlist. However, the name of said individual is largely meaningless, since it is not linked to the creator's professional profile. In the age of rich social media, providing a public profile is almost compulsory and is a welcome feature. Sharing, embedding, and creating lists are aspects of well-integrated online spaces, and the profile of the lists creator is the face behind it-why hide it?

Another useful feature is the View Thumbnails link. This tool, which can be used after locating a particular video, gives the viewer a visual progression of the video using thumbnail screenshots. A user can choose the size of the thumbnail as well as the length of the timeline between screenshots. Selecting a thumbnail will take the viewer to that part of the video, and the frame's exact location is noted in the accompanying transcript. The seamless integration of choice and selection is well appreciated, especially when it comes to lengthier videos or when a visual search is most useful.

\section{HELP}

A Help link is included in the persistent navigation menu at the top of each screen. The Help page includes a list of guides, divided by topic (getting started, browsing, searching, playlists, results, video player screen). The Help page also incudes a search box, a list of FAQs, and technical support contact information. The Help screens were clear and succinct, and the topics were relevant. They would be improved by the use of graphical elements such as screen shots, but they were consise enough not to pose a problem for people with slower reading uptake. Given how difficult it can sometimes be to find a technical support contact, placing this information on the first Help pages was appreciated.

\section{Contract Provisions}

The contract is standard and allows use of the product for educational purposes. This is helpful because so much audiovisual media is bound by confusing intellectual property law. This product is rich with Web 2.0 functionality (such as embedding, visual searches, sharing, and other tools), and we appreciate a product that we can tell faculty is available for all reasonable uses. Collaboration among faculty from various institutions may be limited by the Interlibrary Loan policy: only small amounts of printed material may be sent. Given the value of the materials found in this database, this may cause some frustration among faculty, though you can hardly blame Alexander Street Press for wanting a return on its investment.

\section{Authentication}

Authentication is generally IP based; it worked seamlessly for us using ezproxy for off campus authentication. The license agreement seems to be both standard and fair; it states:

Authorized Users are the Customer's currently enrolled fullor part-time students, employees, faculty, staff, affiliated researchers, distance learners, visiting scholars, including remote access through an authentication (proxy) server that guarantees access only by Authorized Users. Walk-in patrons who are physically present at the Site are also Authorized Users. The 
Product(s) may be used by the licensed number of simultaneous users for which the Customer has paid.

\section{Author's Selected References}

Hebblethwaite, C. L. (2009). Counseling and Psychotherapy Transcripts, Client Narratives, and Reference Works. Retrieved July 17 , 2009: http://www.cro2.org/default.aspx ?page=reviewdisplay\&pid= 3417380.

VandenBos, G. R. (2007). Counseling psychology. In APA Dictionary of Psychology. Washington, D.C.: American Psychological Association.

\section{About the Author}

Memo Cordova is a Reference and Instruction Librarian at Boise State University. He is currently liaison and collection development librarian for the Psychology collection at Boise State University. Memo has worked in public, private, and academic libraries, and received his M.L.I.S. from The University of Washington in 2003.

\section{Contact Information}

Counseling and Therapy in Video

3212 Duke Street

Alexandria, VA 22314

Phone: (800) 889-5937

Fax: (703) 940-6584

E-mail: <gurquhart@astreetpress.com>

URL: <http://alexanderstreet.com/>

Ellie Dworak is the Reference Services Coordinator at Boise State University, where she previously served as Web Services Librarian. She has also worked at San Diego State University as the Electronic Systems and Services Librarian and at Ohio University as a Reference and Instruction Librarian. She has written several reviews for The Charleston Advisor.

\section{Subscribe TO The Charleston Advisor Today!}

\section{The Charleston Advisor: Critical Reviews of Web Products for Information Professionals}

YES! Enter my Subscription for One Year.

\section{Over 500 Reviews Now Included}

- Libraries pay less than $\$ .60$ per review

- Publishers pay less than $\$ 1.00$ per review

\section{How Much Are You Spending?}

- Web Database and Quarterly Print are now available at the low price of $\$ \mathbf{2 9 5 . 0 0}$ for libraries; $\$ \mathbf{4 9 5 . 0 0}$ for all others.

ORDER YOUR SUBSCRIPTION TODAY.

Order on the Web: www.charlestonco.com
Name:

Title:

Organization:

Address:

City/State/Zip:

Phone:Fax:

E-Mail:

$\square$ YES. I am interested in being a Reviewer.

6180 E. Warren Ave., Denver, CO 80222

Phone: (303) 282-9706 Fax: (303)282-9743 